\title{
Research Letter Effect of Postdeposition Annealing on the Structural, Electrical, and Optical Properties of DC Magnetron Sputtered $\mathrm{Ta}_{2} \mathrm{O}_{5}$ Films
}

\author{
S. V. Jagadeesh Chandra, ${ }^{1}$ P. Sreedhara Reddy, ${ }^{1}$ G. Mohan Rao, ${ }^{2}$ and S. Uthanna ${ }^{1}$ \\ ${ }^{1}$ Department of Physics, Sri Venkateswara University, Tirupati 517502, India \\ ${ }^{2}$ Department of Instrumentation, Indian Institute of Science, Bangalore 560012, India
}

Correspondence should be addressed to S. Uthanna, uthanna@rediffmail.com

Received 12 August 2007; Accepted 5 November 2007

Recommended by Maria Antonietta Loi

Thin films of tantalum oxide were formed on quartz and silicon (111) substrates kept at room temperature (303 K) by reactive sputtering of tantalum target in the presence of mixture of oxygen and argon gases. The as-deposited films were annealed in air for an hour in the temperature range $673-873 \mathrm{~K}$. The films were characterized by studying structural, dielectric, electrical, and optical properties. The as-deposited films were amorphous in nature. As the annealing temperature increased to $673 \mathrm{~K}$, the films were transformed into polycrystalline. Electrical characteristics of as-deposited and annealed $\mathrm{Ta}_{2} \mathrm{O}_{5}$ thin films were compared. The thermal annealing reduced the leakage current density and increased the dielectric constant. The optical transmittance of the films increased with the increase of annealing temperature. The as-deposited films showed the optical band gap of $4.38 \mathrm{eV}$. It increased to $4.44 \mathrm{eV}$ with the increase of annealing temperature to $873 \mathrm{~K}$. The as-deposited films showed the low value (1.89) of refractive index and it increased to 2.15 when annealed at $873 \mathrm{~K}$. The increase of refractive index with annealing temperature was due to the increase in the packing density and crystallinity of the films.

Copyright (C) 2007 S. V. Jagadeesh Chandra et al. This is an open access article distributed under the Creative Commons Attribution License, which permits unrestricted use, distribution, and reproduction in any medium, provided the original work is properly cited.

\section{INTRODUCTION}

Tantalum pentoxide $\left(\mathrm{Ta}_{2} \mathrm{O}_{5}\right)$ thin films have been extensively used for optical and electronic applications such as antireflection coatings for silicon solar cells, multilayer interference filters, optical waveguides, and dielectric layers in dynamic random access memory devices and electrochromic devices [1-3]. Many research efforts have been devoted to the structural and optical properties of as-deposited films which suffer from the crystallization difficulty. Hence, it becomes imperative to deposit the films at high substrate temperatures or postdeposition annealing in order to improve the microstructure of the films. At high substrate temperatures, a thick silicon dioxide is formed at the interface of silicon and tantalum oxides, which significantly degrades the physical properties. Therefore, it is necessary to deposit the tantalum oxide films at low substrate temperatures to avoid the formation of silicon dioxide at the interface. Recently, Huang and Chu [4] have effectively enhanced the crystallinity of tantalum oxide films by using argon gas in mixture with wa- ter vapor as the working gas. Many annealing techniques, such as the use of dry oxygen, ultraviolet-generated ozone and plasma, and two-step process of rapid thermal annealing for crystallization of tantalum oxide films, have been used $[5,6]$. Different thin film deposition methods such as pulsed laser deposition, chemical vapor deposition, ion beam evaporation, and DC/RF sputtering [7-12] were employed for the preparation of tantalum oxide films. In this investigation, an attempt is made in the preparation of tantalum oxide films on quartz and silicon substrates held at room temperature $(303 \mathrm{~K})$ by DC magnetron sputtering technique. The as-deposited films were annealed in air for one hour at different temperatures in the range of $673-873 \mathrm{~K}$. The effect of annealing on the structural, dielectric, electrical, and optical properties of the $\mathrm{Ta}_{2} \mathrm{O}_{5}$ films was investigated systematically and reported in the results.

\section{EXPERIMENTATION}

DC magnetron sputtering technique was employed for the preparation of tantalum oxide films on crystalline p-type 
silicon (111) and quartz substrates held at room temperature $(303 \mathrm{~K})$ by sputtering tantalum target in an oxygen partial pressure of $1 \times 10^{-4}$ mbar. An ultimate pressure of $2 \times 10^{-6}$ mbar was obtained in the sputter chamber using diffusion pump and rotary pump combination. Pure oxygen and argon were used as the reactive and sputtering gases, respectively. The sputter pressure maintained during the deposition of the films was $1 \times 10^{-3}$ mbar. The required quantities of oxygen and argon gases were admitted into the sputter chamber through the fine controlled needle valves, and their flow rates were monitored individually using Tylan mass flow controllers. The as-deposited films were annealed in air for one hour at different temperatures in the range of 673-873 K. The films were characterized by studying the chemical binding configuration with Nocolet (model 5700 FTIR) Fourier transform infrared spectrometer in the wavenumber range of $400-4000 \mathrm{~cm}^{-1}$. Electron core-level binding energies of the films were analyzed by the X-ray photoelectron spectrophotometer (model PHI 5700). The crystallographic structure of the films was recorded with Seifert (model 3003 TT) Xray diffractometer in the $2 \theta$ range of $30-65^{\circ}$. Aluminum top electrode of $500 \mathrm{~nm}$ thickness and $3 \mathrm{~mm}$ diameter was deposited by vacuum evaporation in order to study the dielectric properties of the $\mathrm{Al} / \mathrm{Ta}_{2} \mathrm{O}_{5} / \mathrm{Si}$ structure. The capacitancevoltage characteristics of the fabricated $\mathrm{Ta}_{2} \mathrm{O}_{5}$ capacitors were measured using MIOKI (model 3532-50) LCR meter. The current-voltage characteristic of the capacitor was measured using Hewlett Packard (model HP 4140B) pA meter. The optical transmittance of the films was recorded with Hitachi (model U-3400) UV-Vis-NIR spectrophotometer in the wavelength range of $200-800 \mathrm{~nm}$ in order to study the optical properties.

\section{RESULTS AND DISCUSSION}

Figure 1 shows the Fourier transform infrared spectra of asdeposited tantalum oxide films and the films annealed at different temperatures. The spectrum of the as-deposited film showed a prominent absorption band at $630 \mathrm{~cm}^{-1}$ and a broadband in the range of $700-1000 \mathrm{~cm}^{-1}$. The presence of broadband was related to the stretching mode of $\mathrm{Ta}-\mathrm{O}-\mathrm{Ta}$ and $630 \mathrm{~cm}^{-1}$ band corresponding to the stretching mode of $\mathrm{O} \equiv 3 \mathrm{Ta}$. The positions of the vibration bands indicated that the films were amorphous in nature [5]. Similar predominant band at about $600 \mathrm{~cm}^{-1}$ was also noticed in spin-coated $\mathrm{Ta}_{2} \mathrm{O}_{5}$ films [13]. When the films were annealed at a temperature of $673 \mathrm{~K}$, the intensity of $630 \mathrm{~cm}^{-1}$ band decreased with the appearance of an additional shoulder at about $520 \mathrm{~cm}^{-1}$. The presence of the shoulder corresponds to the stretching mode of tantalum oxide in the polycrystalline phase. It also showed the presence of another band at about $820 \mathrm{~cm}^{-1}$ related to the stretching mode of $\mathrm{Ta}-\mathrm{O}-\mathrm{Ta}$ of tantalum oxide films in the polycrystalline phase. With further increase of annealing temperature to $873 \mathrm{~K}$, a distinct band at $510 \mathrm{~cm}^{-1}$ was observed along with the bands at 630 and $820 \mathrm{~cm}^{-1}$. It clearly indicated that the crystallinity of the films improved with the increase of annealing temperature. Park et al. [14] observed a prominent band at $635 \mathrm{~cm}^{-1}$ in the case of amorphous tantalum oxide films formed at $303 \mathrm{~K}$, while the band

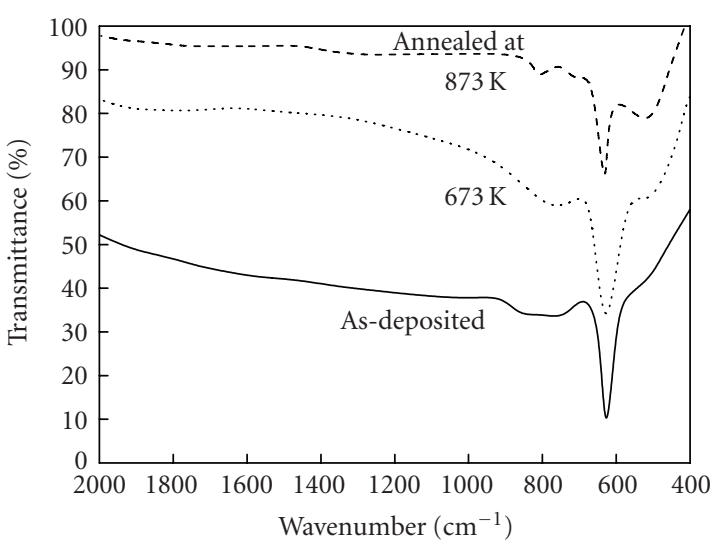

FIgURE 1: FTIR spectra of as-deposited and annealed $\mathrm{Ta}_{2} \mathrm{O}_{5}$ films.

at $510 \mathrm{~cm}^{-1}$ was noticed when films were annealed at $1223 \mathrm{~K}$. Recently, Atanassova et al. [15] observed an increase in the intensity of absorption bands at 650 and $520 \mathrm{~cm}^{-1}$ with the increase of substrate temperature in laser deposited tantalum oxide films.

Figures 2(a) and 2(b) show the narrow scan X-ray photoelectron spectra of as-deposited and annealed $\mathrm{Ta}_{2} \mathrm{O}_{5}$ films recorded in the binding energy ranges of $24-30 \mathrm{eV}$ and $527-$ $533 \mathrm{eV}$ for core-level binding energies of $\mathrm{Ta} 4 \mathrm{f}$ and $\mathrm{O} 1 \mathrm{~s}$, respectively. In the case of as-deposited films, the peaks observed at 25.9 and $27.8 \mathrm{eV}$ related to the Ta $4 \mathrm{f}_{7 / 2}$ and $\mathrm{Ta} 4 \mathrm{f}_{5 / 2}$ core levels of $\mathrm{Ta}^{5+}$ were observed [4]. When the films were annealed to $873 \mathrm{~K}$, the binding energies of $\mathrm{Ta} 4 \mathrm{f}_{7 / 2}$ and $\mathrm{Ta}$ $4 \mathrm{f}_{5 / 2}$ were shifted to 26.3 and $28.2 \mathrm{eV}$. The films annealed at $873 \mathrm{~K}$ were completely oxidized; hence they were nearly stoichiometric with a chemical shift of $4.3 \mathrm{eV}$. The core-level binding energy of $\mathrm{O} 1 \mathrm{~s}$ in as-deposited film was $529.9 \mathrm{eV}$. In the case of the films annealed at $873 \mathrm{~K}$, the binding energy shifted to $530.2 \mathrm{eV}$ due to the characteristic of $\mathrm{O}^{2-}$ anion in the oxide.

Figure 3 shows the X-ray diffraction profiles of asdeposited films as well as the films annealed at different temperatures. X-ray diffraction pattern of the as-deposited films does not contain any reflection indicating that the films were amorphous. When the films were annealed at $673 \mathrm{~K}$, three peaks were observed at $2 \theta=36.26^{\circ}, 39.46^{\circ}$, and $59.3^{\circ}$ corresponding to (1 1111 ), (261), and (400) reflections of orthorhombic $\beta$-phase of tantalum oxide. In addition to this, small peaks observed at $44.52^{\circ}$ and $51.94^{\circ}$ were related to the (330) and (351) reflections of tantalum oxide. Increasing annealing temperature to $873 \mathrm{~K}$, the crystallinity of the films increased. In addition to this, the peak at $39.46^{\circ}$ disappeared. The observed reflections were in good agreement with the tantalum oxide JCPDS (71-0639) data. It was reported that the films formed by physical vapor deposition techniques at room temperature were amorphous, whereas the crystallinity of the films set in above $673 \mathrm{~K}$ [15]. Pignolet et al. [5] obtained amorphous films at room temperature, and the crystallinity set in at $973 \mathrm{~K}$ either by rapid thermal annealing or conventional annealing. Kimura et al. [16] obtained the crystalline films when annealed at $948 \mathrm{~K}$. In the 


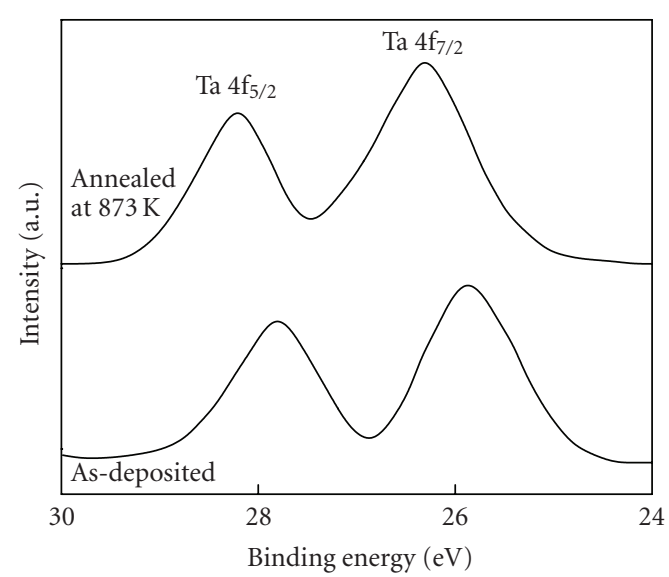

(a)

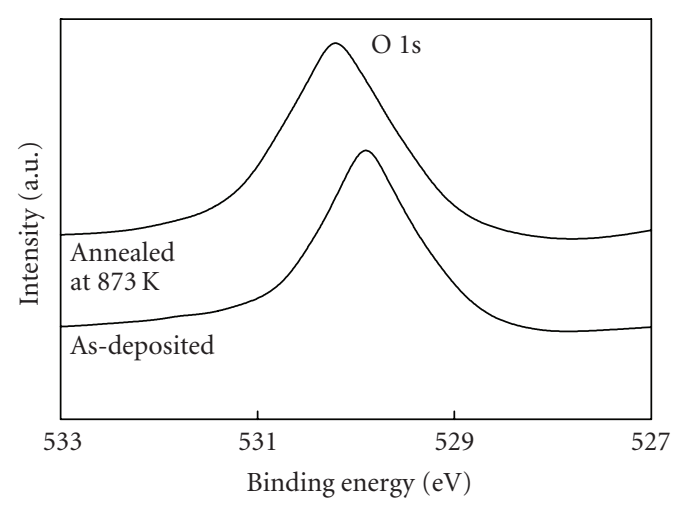

(b)

FIGURE 2: XPS core-level binding energy spectra of $\mathrm{Ta}_{2} \mathrm{O}_{5}$ films: (a) Ta $4 \mathrm{f}$ and (b) O $1 \mathrm{~s}$.

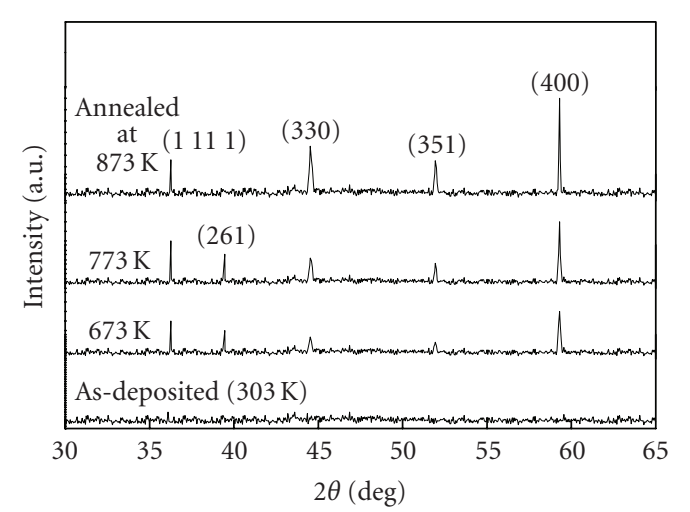

FIgURE 3: X-ray diffraction spectra of as-deposited and annealed $\mathrm{Ta}_{2} \mathrm{O}_{5}$ films.

present study, it is to be noted that the setting-in of the polycrystalline films was at the annealing temperature of $673 \mathrm{~K}$. The crystallite size of the films evaluated from the diffraction peak of (400) increased from 12 to $18 \mathrm{~nm}$ with the increase of annealing temperature from 673 to $873 \mathrm{~K}$, respectively.

The dielectric constant $(\varepsilon)$ of $\mathrm{Al} / \mathrm{Ta}_{2} \mathrm{O}_{5} / \mathrm{Si}$ capacitor was obtained from the capacitance measurement at the fixed fre-

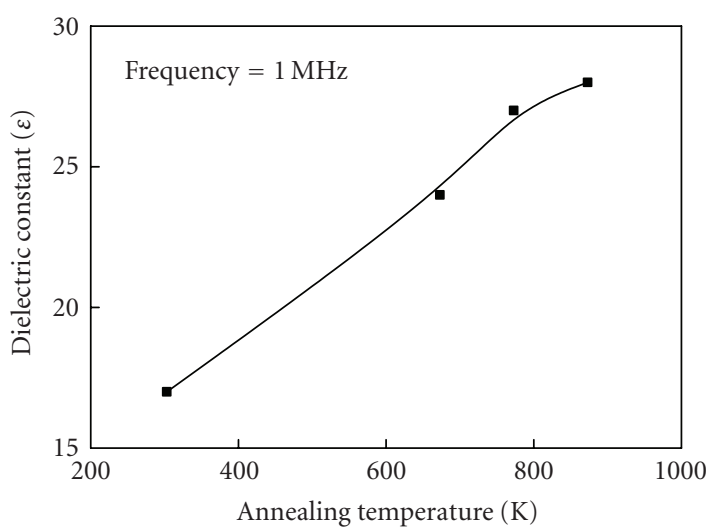

Figure 4: Dependence of dielectric constant on the annealing temperature of $\mathrm{Ta}_{2} \mathrm{O}_{5}$ films.

quency of $1 \mathrm{MHz}$. Figure 4 shows the dependence of dielectric constant on the annealing temperature of $\mathrm{Ta}_{2} \mathrm{O}_{5}$ films. The dielectric constant of the as-deposited film was 17 . When the annealing temperature increased to $873 \mathrm{~K}$, the dielectric constant increased to a value of 28 . The low dielectric constant observed in the as-deposited film can be explained in terms of noncrystalline state which was supported by the Fourier transform infrared spectra and X-ray diffraction analysis. The increase of dielectric constant with the increase of annealing temperature was due to the crystalline nature of $\mathrm{Ta}_{2} \mathrm{O}_{5}$ and the increase in the densification of dielectric layer after annealing [17]. When the films were annealed, the oxygen diffused into $\mathrm{Ta}_{2} \mathrm{O}_{5}$ and reduced the oxygen vacancies hence increase in the dielectric constant. It was also reported that the dielectric constant increased with the temperature in rapid thermal annealed RF sputtered $\mathrm{Ta}_{2} \mathrm{O}_{5}$ films [18].

Leakage current density $(\mathrm{J})$ of the $\mathrm{Al} / \mathrm{Ta}_{2} \mathrm{O}_{5} / \mathrm{Si}$ capacitors as a function of applied voltage is shown in Figure 5. Annealing treatment led to the reduction of the leakage current. The leakage current density of the as-deposited film was independent on the applied voltage. Leakage current density at bias voltage of $0.1 \mathrm{~V}$ of the films annealed at $673 \mathrm{~K}$ was $7.1 \times 10^{-9} \mathrm{~A} / \mathrm{cm}^{2}$; it decreased to $1.2 \times 10^{-9} \mathrm{~A} / \mathrm{cm}^{2}$ when films were annealed at $873 \mathrm{~K}$. The decrease of leakage current density was due to the presence of crystalline phase; the additional oxidation may improve the quality of the interface.

The optical transmittance of the as-deposited films as well as the films annealed at 673 and $873 \mathrm{~K}$ is shown in Figure 6. The optical transmittance of the as-deposited film was about $65 \%$ at wavelengths $(\lambda)$ above $500 \mathrm{~nm}$. This low optical transmittance in as-deposited films may be due to the presence of unreacted tantalum along with $\mathrm{Ta}_{2} \mathrm{O}_{5}$ in the films. When the annealing temperature increased to $873 \mathrm{~K}$, the optical transmittance of the films increased to $82 \%$. A sharp absorption edge was observed at about $280 \mathrm{~nm}$. The optical absorption edge of the films shifted towards the lower wavelength side with the increase of annealing temperature. The optical absorption coefficient $(\alpha)$ of the films was evaluated from the optical transmittance data where the reflection losses were taken into account. The optical bandgap of 


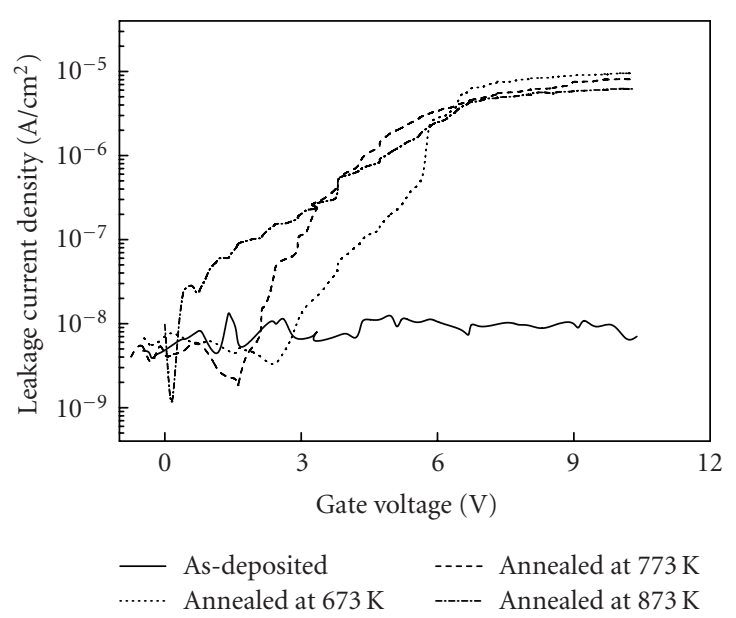

Figure 5: J-V curves of as-deposited and annealed $\mathrm{Ta}_{2} \mathrm{O}_{5}$ films.

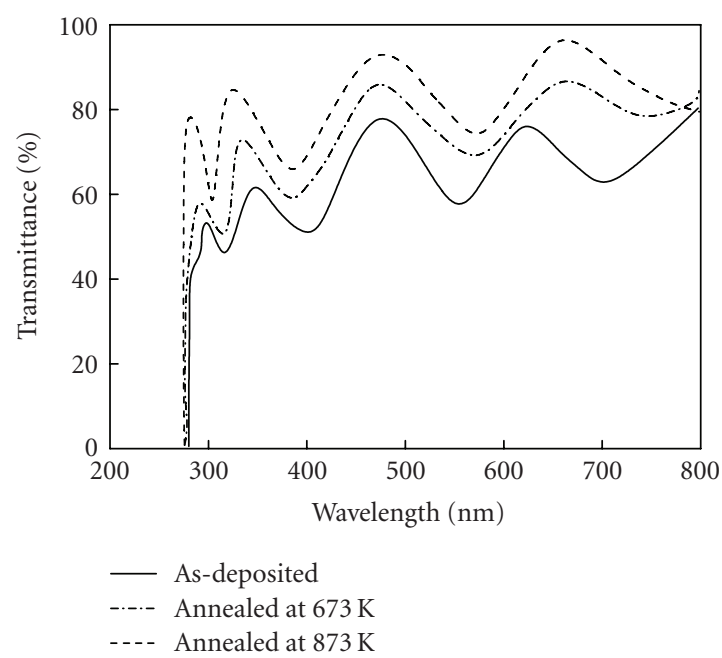

FIgURE 6: Optical transmittance spectra of as-deposited and annealed $\mathrm{Ta}_{2} \mathrm{O}_{5}$ films.

the films was estimated from the plots of $(\alpha \mathrm{h} v)^{2}$ versus photon energy $(h v)$ by extrapolating the linear portion of the plots to $\alpha=0$. The optical bandgap of the as-deposited film was $4.38 \mathrm{eV}$. The optical bandgap of the films increased to $4.44 \mathrm{eV}$ with the increase of annealing temperature to $873 \mathrm{~K}$. The optical bandgap obtained in the annealed films was in good agreement with the reports of reactive sputtered films [19]. The refractive index of the films was determined from the interference of the optical transmittance data employing Swanepoel's envelope method [20].

The refractive index $(n)$ of the as-deposited film (at $\lambda>$ $500 \mathrm{~nm}$ ) was 1.89. It increased to 2.15 with the increase of annealing temperature to $873 \mathrm{~K}$. The observed low refractive index in as-deposited films was due to the low packing density of the films because of the amorphous nature. The refractive index of the films increased with the increase of annealing temperature due to improvement in the packing density [3] and the polycrystalline nature of the films. The achieved re- fractive index was in agreement with the RF magnetron [18] and pulsed DC magnetron [21] sputtered films.

\section{CONCLUSIONS}

Tantalum oxide films were deposited on quartz and crystalline silicon substrates held at room temperature by sputtering of tantalum target in the presence of an oxygen partial pressure of $1 \times 10^{-4} \mathrm{mbar}$ and at the sputtering pressure of $1 \times 10^{-3}$ mbar employing DC magnetron sputtering. The as-deposited films were annealed in air for one hour in the temperature range of $673-873 \mathrm{~K}$. The effect of annealing on the chemical binding configuration, crystal structure, dielectric, electrical, and optical properties of tantalum oxide films was studied. The Fourier transform infrared studies revealed that as-deposited films were amorphous. While the annealing temperature increased to $873 \mathrm{~K}$, the films were polycrystalline. This was also confirmed by the $\mathrm{X}$-ray diffraction studies. The dielectric constant showed a maximum value of 28 for the films annealed at $873 \mathrm{~K}$. The leakage current density decreased from $3.1 \times 10^{-9}$ to $1.2 \times 10^{-9} \mathrm{~A} / \mathrm{cm}^{2}$ with the increase of annealing temperature from 673 to $873 \mathrm{~K}$. The increase of optical bandgap from 4.38 to $4.44 \mathrm{eV}$ and the refractive index from 1.89 to 2.15 for the as-deposited films and the films annealed at $873 \mathrm{~K}$ was due to the improvement in the crystallinity and the packing density.

\section{ACKNOWLEDGMENTS}

This work was carried out with the financial support of University Grants Commission, New Delhi, through research Project no. F.30-4/2004 (SR). The authors are thankful to Dr. Andreas Klein, Institute of Materials Science, Darmstadt University of Technology, Germany, for extending the XPS facility.

\section{REFERENCES}

[1] C. Chaneliere, J. L. Autran, R. A. B. Devine, and B. Balland, "Tantalum pentoxide $\left(\mathrm{Ta}_{2} \mathrm{O}_{5}\right)$ thin films for advanced dielectric applications," Materials Science and Engineering R, vol. 22, no. 6, pp. 269-322, 1998.

[2] S. Ezhilvalavan and T. Y. Tseng, "Preparation and properties of tantalum pentoxide $\left(\mathrm{Ta}_{2} \mathrm{O}_{5}\right)$ thin films for ultra large scale integrated circuits (ULSIs) application-a review," Journal of Materials Science: Materials in Electronics, vol. 10, no. 1, pp. 9-31, 1999.

[3] L. Pereira, P. Barquinha, E. Fortunato, et al., "High k dielectrics for low temperature electronics," Thin Solid Films, In Press.

[4] A. P. Huang and P. K. Chu, "Crystallization improvement of $\mathrm{Ta}_{2} \mathrm{O}_{5}$ thin films by the addition of water vapor," Journal of Crystal Growth, vol. 274, no. 1-2, pp. 73-77, 2005.

[5] A. Pignolet, G. Mohan Rao, and S. B. Krupanidhi, "Rapid thermal processed thin films of reactively sputtered $\mathrm{Ta}_{2} \mathrm{O}_{5}$," Thin Solid Films, vol. 258, no. 1-2, pp. 230-235, 1995.

[6] H. Zhang, R. Solanki, B. Roberds, G. Bai, and I. Banerjee, "High permittivity thin film nanolaminates," Journal of Applied Physics, vol. 87, no. 4, pp. 1921-1924, 2000.

[7] C. J. Huang, "Room-temperature formation of tantalum oxide films by liquid phase deposition," Thin Solid Films, vol. 478, no. 1-2, pp. 332-337, 2005. 
[8] C. H. Liu, S. J. Chang, J. F. Chen, S. C. Chen, J. S. Lee, and U. H. Liaw, "High-quality ultrathin chemical-vapor-deposited $\mathrm{Ta}_{2} \mathrm{O}_{5}$ capacitors prepared by high-density plasma annealing," Materials Science and Engineering B, vol. 106, no. 3, pp. 234241, 2004.

[9] S. G. Yoon, H. K. Kim, M. J. Kim, H. M. Lee, and D. H. Yoon, "Effect of substrate temperature on surface roughness and optical properties of $\mathrm{Ta}_{2} \mathrm{O}_{5}$ using ion-beam sputtering," Thin Solid Films, vol. 475, no. 1-2, pp. 239-242, 2005.

[10] T. Ono, K. Kato, H. Toyata, Y. Fukuda, and Y. Jin, "Characterization of metal insulator metal electrical properties of electron cyclotron resonance plasma deposited $\mathrm{Ta}_{2} \mathrm{O}_{5}$," Japanese Journal of Applied Physics, vol. 45, no. 9B, pp. 7345-7350, 2006.

[11] N. Novkovski, E. Atanassova, and A. Paskaleva, "Stressinduced leakage currents of the RF sputtered $\mathrm{Ta}_{2} \mathrm{O}_{5}$ on Nimplanted silicon," Applied Surface Science, vol. 253, no. 9, pp. 4396-4403, 2007.

[12] S. V. Jagadeesh Chandra, G. Mohan Rao, and S. Uthanna, "Heat treatment induced structural and optical properties of rf magnetron sputtered tantalum oxide films," Crystal Research and Technology, vol. 42, no. 3, pp. 290-294, 2007.

[13] F. E. Ghodsi, F. Z. Tepehan, and G. G. Tepehan, "Optical properties of $\mathrm{Ta}_{2} \mathrm{O}_{5}$ thin films deposited using the spin coating process," Thin Solid Films, vol. 295, no. 1-2, pp. 11-15, 1997.

[14] S. W. Park, Y. K. Baek, I. Y. Lee, C. O. Park, and H. B. Im, "Effects of annealing conditions on the properties of tantalum oxide films on silicon substrates," Journal of Electronic Materials, vol. 21, no. 6, pp. 635-639, 1992.

[15] E. Atanassova, G. Aygun, R. Turan, and T. Babeva, "Structural and optical characteristics of tantalum oxide grown by pulsed Nd:YAG laser oxidation," Journal of Vacuum Science and Technology A, vol. 24, no. 2, pp. 206-211, 2006.

[16] S.-I. Kimura, Y. Nishioka, A. Shintani, and N. Mukai, "Leakage-current increase in amorphous Ta//2O//5 films due to pinhole growth during annealing below 600 degree C," Journal of the Electrochemical Society, vol. 130, no. 12, pp. 24142418, 1983.

[17] E. Atanassova, N. Novkovski, A. Paskaleva, and M. PecovskaGjorgjevich, "Oxygen annealing modification of conduction mechanism in thin rf sputtered $\mathrm{Ta}_{2} \mathrm{O}_{5}$ on Si," Solid-State Electronics, vol. 46, no. 11, pp. 1887-1898, 2002.

[18] E. Atanassova, M. Kalitzova, and G. Zollo, "High temperatureinduced crystallization in tantalum pentoxide layers and its influence on the electrical properties," Thin Solid Films, vol. 426, no. 1-2, pp. 191-199, 2003.

[19] F. Rubio, "Optical properties of reactively sputtered $\mathrm{Ta}_{2} \mathrm{O}_{5}$ films," Journal of Vacuum Science and Technology, vol. 21, no. 4, pp. 1043-1045, 1982.

[20] R. Swanepoel, "Determination of the thickness and optical constants of amorphous silicon," Journal of Physics E, vol. 16, no. 12 , pp. 1214-1222, 1983.

[21] C. Wang, L. Fang, G. Zhang, D.-M. Zhuang, and M.-S. Wu, " $I-V$ characteristics of tantalum oxide film and the effect of defects on its electrical properties," Thin Solid Films, vol. 458, no. 1-2, pp. 246-250, 2004. 

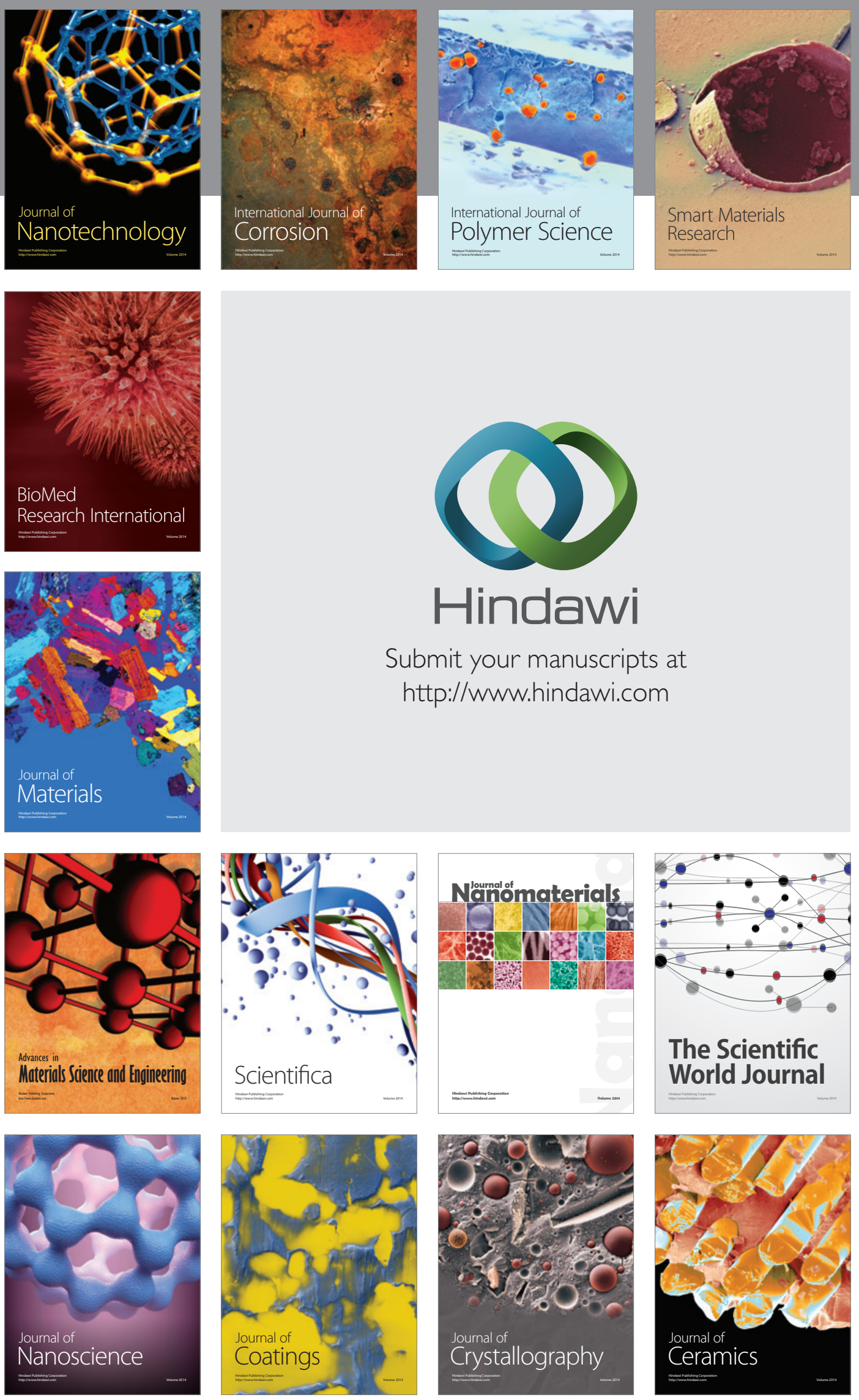

The Scientific World Journal

Submit your manuscripts at

http://www.hindawi.com

\section{World Journal}

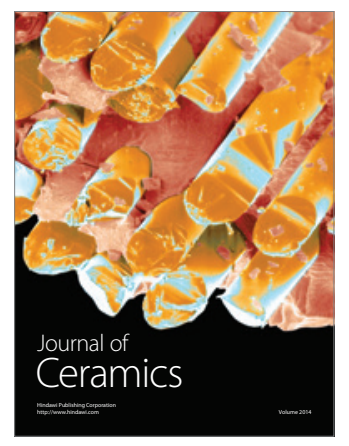

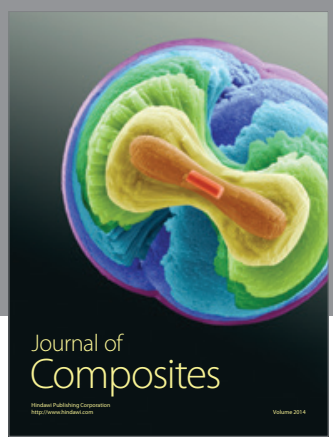
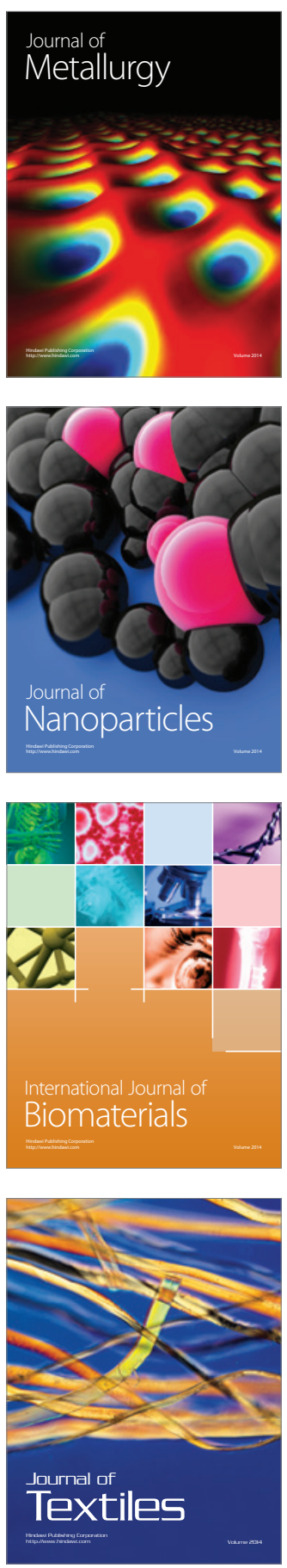